\title{
Preparo do solo e doses de nitrogênio em cobertura em arroz de terras altas ${ }^{1}$
}

\author{
Antônio Eduardo Fonseca², Orivaldo $\mathrm{Arf}^{3}$, \\ Valdeci Orioli Júnior ${ }^{4}$, Salatier Buzetti ${ }^{5}$, Ricardo Antônio Ferreira Rodrigues ${ }^{5}$
}

\begin{abstract}
Soil management and

topdressing nitrogen doses on upland rice

The influences of soil management and nitrogen fertilization are not well defined for upland rice. Thus, this research was carried out to evaluate the yield components, milled grain yield, and grain yield of upland rice cultivars under sprinkler irrigation, according to soil management and topdressing nitrogen doses. The experiment was conducted in Selvíria, Mato Grosso do Sul State, Brazil, under field conditions, for two consecutive harvest times: 2003/2004 (BRS Talento cultivar) and 2004/2005 (IAC 202 cultivar). The randomized blocks design was adopted, consisting of the combination of three soil management systems (disc harrow + leveling disc harrow, scarifier + leveling disc harrow, and no-till $)$ and six topdressing nitrogen doses $\left(0 \mathrm{~kg} \mathrm{ha}^{-1}\right.$, $25 \mathrm{~kg} \mathrm{ha}^{-1}, 50 \mathrm{~kg} \mathrm{ha}^{-1}, 75 \mathrm{~kg} \mathrm{ha}^{-1}, 100 \mathrm{~kg} \mathrm{ha}^{-1}$, and $\left.125 \mathrm{~kg} \mathrm{ha}^{-1}\right)$, with four replications. The leaf $\mathrm{N}$ concentration, plant height, yield components, milled grain yield, and grain yield were evaluated. The scarifier + leveling disc harrow system provided the highest grain yield for both cultivars, while the topdressing nitrogen fertilization just affected the IAC 202 cultivar yield, without affecting the milled grains yield.
\end{abstract}

KEY-WORDS: Oryza sativa L.; nitrogen fertilization; no-till system.

\section{INTRODUÇÃO}

$\mathrm{O}$ arroz é importante fonte de calorias e proteínas, na dieta alimentar do povo brasileiro. No entanto, por conta da oscilação na sua produção, eventualmente, a importação deste cereal tem sido necessária, para suprir a demanda do País (Arf et al. 2001). Neste sentido, esforços com o intuito de elevar a produção de arroz, no Brasil, são importantes. Den-

\section{RESUMO}

As influências do sistema de preparo do solo e da adubação nitrogenada não estão bem definidas para o arroz de terras altas. Assim, com o objetivo de avaliar os componentes da produtividade e o rendimento industrial do arroz de terras altas irrigado por aspersão, em função do preparo do solo e de doses de nitrogênio em cobertura, conduziu-se o experimento em condições de campo, em Selvíria (MS), por duas safras consecutivas: 2003/2004 (cultivar BRS Talento) e 2004/2005 (cultivar IAC 202). Adotou-se o delineamento em blocos casualizados, constituído pela combinação de três manejos de solo (grade aradora + grade niveladora, escarificador + grade niveladora e plantio direto) e seis doses de $\mathrm{N}$ em cobertura (0 kg ha-1, $25 \mathrm{~kg} \mathrm{ha}^{-1}, 50 \mathrm{~kg} \mathrm{ha}^{-1}, 75 \mathrm{~kg} \mathrm{ha}^{-1}, 100 \mathrm{~kg} \mathrm{ha}^{-1} \mathrm{e}$ $\left.125 \mathrm{~kg} \mathrm{ha}^{-1}\right)$, com quatro repetições. Avaliou-se a concentração de $\mathrm{N}$ na folha, altura de plantas, componentes de produção, produtividade e o rendimento industrial dos grãos. O preparo do solo com escarificador + grade niveladora propiciou a obtenção de maiores produtividades das duas cultivares, enquanto a adubação nitrogenada em cobertura interferiu apenas na produtividade da cultivar IAC 202, sem afetar o rendimento industrial de grãos.

PALAVRAS-CHAVE: Oryza sativa L.; adubação nitrogenada; plantio direto.

tre os fatores que podem afetar, significativamente, a produção de arroz de terras altas, o preparo do solo tem despertado atenção.

A despeito das vantagens do sistema plantio direto, frequentemente a produção de arroz de terras altas sob este sistema tem ficado abaixo da obtida com o sistema convencional. Isto tem sido atribuído, principalmente, ao menor desenvolvimento das raízes das plantas cultivadas neste sistema, acarretando

1. Trabalho recebido em fev./2012 e aceito para publicação em ago./2012 ( ${ }^{\circ}$ registro: PAT 16933).

2. Fundo de Defesa da Citricultura (Fundecitrus), Araraquara, SP, Brasil.E-mail: eduardofonseca51@hotmail.com.

3. Universidade Estadual Paulista (Unesp), Faculdade de Engenharia, Departamento de Fitotecnia, Tecnologia de Alimentos e Socioeconomia, Ilha Solteira, SP, Brasil.E-mail: arf@agr.feis.unesp.br.

4. Universidade Estadual Paulista (Unesp), Faculdade de Ciências Agrárias e Veterinárias (FCAV), Departamento de Solos e Adubos, Jaboticabal, SP, Brasil.E-mail: orioli.jr@hotmail.com.

5. Universidade Estadual Paulista (Unesp), Faculdade de Engenharia, Departamento de Fitossanidade, Engenharia Rural e Solos, Ilha Solteira, SP, Brasil.E-mails: sbuzetti@agr.feis.unesp.br, ricardo@agr.feis.unesp.br. 
redução na tolerância à falta d'água e, consequentemente, menor número de perfilhos e de panículas por área. Aparentemente ocorre, também, redução no desenvolvimento das plantas, sobretudo durante a fase vegetativa (Soares 2004).

De acordo com Seguy et al. (1989), o arroz é a cultura mais sensível, quanto à qualidade física do solo, e pequenas alterações na porosidade do solo podem afetar, significativamente, a cultura. Seguy \& Bouzinac (1992) observaram menor rendimento de arroz de terras altas no sistema plantio direto, intermediário para o preparo com grade aradora, e maior quando efetuada aração profunda do solo. Por estes motivos, $\mathrm{o}$ arroz de terras altas não tem sido utilizado com frequência na rotação de culturas do sistema plantio direto, o que vem reduzindo o seu cultivo.

Alguns produtores têm adotado o preparo do solo com escarificador como alternativa ao sistema convencional. Esse tipo de preparo do solo pode propiciar condições mais adequadas ao desenvolvimento das raízes em profundidade, o que possibilita que as plantas utilizem água das camadas mais profundas do solo e explorem nutrientes em maior volume de solo, beneficiando o enchimento de grãos. Além disto, ao provocar pequeno revolvimento superficial, faz com que o preparo com escarificador preserve parcialmente a agregação do solo, favorecendo a absorção de água e nutrientes (Arf et al. 2002).

Por outro lado, Seguy et al. (1998) afirmam que faltam apenas alguns ajustes para tornar a cultura viável sob plantio direto, e que, sob determinadas condições, a produtividade é igual, ou até superior, à do sistema convencional. Reis et al. (2007) verificaram, durante duas safras, que a produção de grãos de arroz de terras altas no sistema plantio direto e convencional foram semelhantes. Do mesmo modo, Arf et al. (2003) observaram que o sistema plantio direto propiciou produções semelhantes, ou superiores, às obtidas com o preparo do solo com grade ou com arado de aiveca, o que mostra a possibilidade da adoção do sistema plantio direto para a cultura do arroz de terras altas.

Dependendo do sistema de cultivo adotado, são necessários ajustes no manejo da adubação, particularmente com nitrogênio $(\mathrm{N})$, devido à sua complexa dinâmica no ambiente. $\mathrm{O} N$ é um elemento que se perde facilmente por lixiviação, volatilização da amônia e desnitrificação no solo, e a intensidade destes processos pode ser alterada pelo sistema de preparo do solo, como observado por Rojas et al.
(2012), quanto às perdas de $\mathrm{N}$ por volatilização de amônia. Ademais, não existe, ainda, indicação oficial de adubação para o sistema plantio direto, sendo a recomendação atual baseada em pesquisas desenvolvidas sob preparo convencional do solo (Arf et al. 2005).

$\mathrm{O}$ efeito do $\mathrm{N}$ no crescimento das plantas de arroz é observado, geralmente, pelo aumento do número de perfilhos e de panículas por área, número e massa de grãos, que determinam a produção final (Fageria 1984).

Neste sentido, objetivou-se avaliar os efeitos de três sistemas de preparo do solo e de doses de nitrogênio em cobertura sobre os componentes da produtividade e o rendimento industrial do arroz de terras altas irrigado por aspersão.

\section{MATERIAL E MÉTODOS}

O experimento foi conduzido nas safras agrícolas 2003/2004 e 2004/2005, no município de Selvíria (MS), em área experimental pertencente à Faculdade de Engenharia da Unesp, Campus de Ilha Solteira (aproximadamente $20^{\circ} 22^{\prime} \mathrm{S}, 51^{\circ} 22^{\prime} \mathrm{W}$ e altitude de $335 \mathrm{~m}$ ). A precipitação média anual é de $1.370 \mathrm{~mm}$, a temperatura média do ar anual de $23,5^{\circ} \mathrm{C}$ e a umidade relativa do ar de $70-80 \%$ (média anual). Os dados diários de precipitação e temperatura média do ar, durante o período do experimento, estão apresentados na Figura 1.

O solo do local é um Latossolo Vermelho distrófico típico argiloso (Embrapa 2006) e apresentava, na camada $0-0,20 \mathrm{~m}$, os seguintes atributos químicos: $\mathrm{pH}\left(\mathrm{CaCl}_{2}\right)=4,9$; $\mathrm{P}$ (resina) $=$ $22 \mathrm{mg} \mathrm{dm}^{-3} ; \mathrm{K}=0,4 \mathrm{cmol}_{\mathrm{c}} \mathrm{dm}^{-3} ; \mathrm{Ca}=2,3 \mathrm{cmol}_{\mathrm{c}} \mathrm{dm}^{-3}$; $\mathrm{Mg}=1,2 \mathrm{cmol}_{\mathrm{c}} \mathrm{dm}^{-3} ; \mathrm{H}+\mathrm{Al}=3,1 \mathrm{cmol}_{\mathrm{c}} \mathrm{dm}^{-3} ; \mathrm{CTC}=$ $7,0 \mathrm{cmol}_{\mathrm{c}} \mathrm{dm}^{-3} ; \mathrm{V}=56 \%$.

$\mathrm{O}$ delineamento experimental foi o de blocos casualizados, com quatro repetições, em esquema fatorial $3 \times 6$, com os tratamentos constituídos pela combinação de três sistemas de preparo do solo (grade aradora + grade niveladora, escarificador + grade niveladora e plantio direto) e seis doses de nitrogênio em cobertura $\left(0 \mathrm{~kg} \mathrm{ha}^{-1}, 25 \mathrm{~kg} \mathrm{ha}^{-1}, 50 \mathrm{~kg} \mathrm{ha}^{-1}\right.$, $75 \mathrm{~kg} \mathrm{ha}^{-1}, 100 \mathrm{~kg} \mathrm{ha}^{-1}$ e $\left.125 \mathrm{~kg} \mathrm{ha}^{-1}\right)$. A área sob plantio direto encontrava-se neste sistema desde 1996/1997.

A adubação nitrogenada em cobertura, nas duas safras, foi realizada aos 35 dias após a emergência das plantas (Figura 1), utilizando-se, como fonte, a 

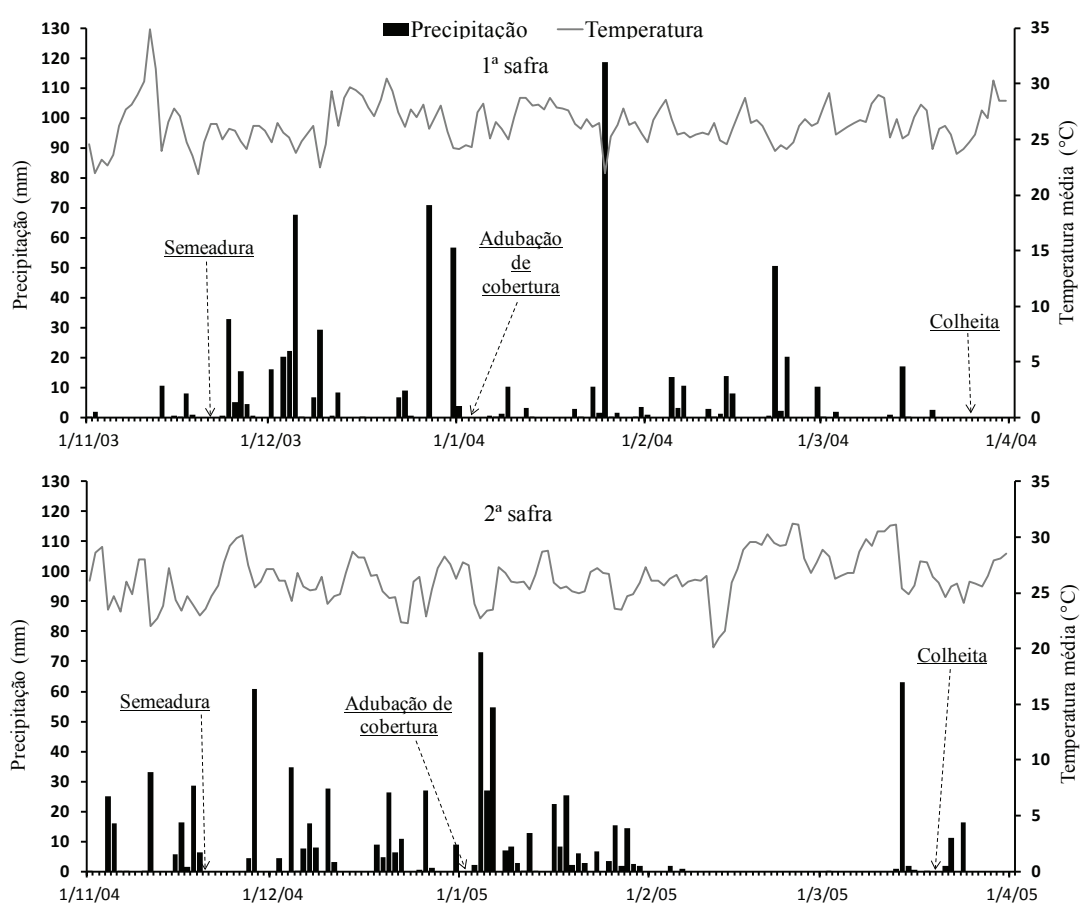

Figura 1. Dados diários de precipitação pluviométrica e temperatura média do ar (Selvíria, MS, safras 2003/2004 e 2004/2005).

ureia. Logo após a aplicação, a área foi irrigada, para minimizar as perdas do nutriente por volatilização.

Para o fornecimento de água, foi utilizado um sistema fixo de irrigação por aspersão, com precipitação média de $3,3 \mathrm{~mm} \mathrm{~h}^{-1}$ nos aspersores. No manejo de água, foram utilizados até três coeficientes de cultura (Kc), distribuídos em quatro períodos, compreendidos entre a emergência e a colheita. Na fase vegetativa, foi utilizado um valor de Kc de 0,4; na fase reprodutiva, um valor inicial de 0,70 e um final de 1,00; e, na fase de maturação, estes valores foram invertidos, ou seja, o inicial foi de 1,00 e o final de 0,70 .

A adubação básica nos sulcos de semeadura constituiu-se da aplicação de $250 \mathrm{~kg} \mathrm{ha}^{-1}$ da fórmula 08-28-16, em ambas as safras, determinada de acordo com as características químicas do solo, levando-se em consideração as recomendações de Cantarella \& Furlani (1996). A semeadura do arroz foi realizada nos dias 24/11/2003 e 23/11/2004 (Figura 1), utilizando-se as cultivares BRS Talento, na primeira safra, e IAC 202, na segunda safra.

As parcelas foram constituídas por cinco linhas de $6,0 \mathrm{~m}$ de comprimento, espaçadas em $0,40 \mathrm{~m} \mathrm{e}$ $0,35 \mathrm{~m}$ entre si, na primeira e segunda safras, respectivamente. No caso do plantio direto, a dessecação da cobertura do solo (milheto) foi realizada com o herbicida gliphosate (1.560 $\mathrm{g} \mathrm{ha}^{-1}$ do i.a.).
A colheita foi realizada manualmente, utilizando-se, como área útil, as três linhas centrais de cada parcela (desprezando-se 0,50 $\mathrm{m}$ em ambas as extremidades), quando $90 \%$ das panículas apresentavam grãos com coloração típica de maduros. Foram realizadas, ainda, as seguintes avaliações:

a) Teor total de $\mathrm{N}$ na folha: utilizou-se metodologia de coleta proposta por Cantarella \& Furlani (1996), sendo coletadas 30 folhas bandeira por parcela, ao acaso, no início do florescimento, e analisadas conforme Malavolta et al. (1997);

b) Altura de plantas: durante o estádio de grão pastoso, foi medida, em 10 plantas por parcela, a distância compreendida entre a superfície do solo e a extremidade superior da panícula mais alta;

c) Número de panículas $\mathrm{m}^{-2}$ : por ocasião da colheita, contou-se o número de panículas em 1,0 m da linha de semeadura, e, posteriormente, os dados foram transformados para $\mathrm{m}^{2}$;

d) Número de grãos por panícula: determinou-se, na colheita, o número de grãos em 15 panículas de cada parcela;

e) Número de grãos granados e chochos por panícula: determinado em 15 panículas, após separação dos grãos por meio de fluxo de ar;

f) Massa de 100 grãos: determinada por meio da coleta e pesagem de duas amostras de 100 grãos 
de cada parcela (13\% base úmida);

g) Produtividade de grãos: determinada pesando-se os grãos em casca, corrigindo-se a umidade para $13 \%$ e convertendo-se para $\mathrm{kg} \mathrm{ha}^{-1}$;

h) Rendimento industrial de grãos: uma amostra de $100 \mathrm{~g}$ de grãos de arroz em casca foi processada em engenho de prova Suzuki, modelo MT, durante 1 minuto. A seguir, foi determinada a massa de grãos brunidos (polidos) e os resultados expressos em percentagem. Posteriormente, os grãos brunidos foram colocados no "Trieur" $\mathrm{n}^{\mathrm{o}} 2$, durante 30 segundos, para separação, por pesagem, do rendimento de grãos inteiros e de grãos quebrados, ambos expressos em percentagem.

Os dados foram submetidos a análise de variância e, quando constatadas diferenças entre os tratamentos, procedeu-se ao teste Tukey, a 5\%, para o fator preparo do solo, e análise de regressão, para doses de $\mathrm{N}$ em cobertura.

\section{RESULTADOS E DISCUSSÃO}

Na safra 2003/2004, o preparo com escarificador favoreceu o crescimento das plantas de arroz em altura, em relação aos outros tipos de preparo (Tabela 1). Possivelmente, o preparo mais profundo do solo tenha permitido que as raízes das plantas explorassem maior volume de solo. Houve, também, aumento na altura das plantas, devido à adição de $\mathrm{N}$ (Tabela 1). O N compõe a molécula de clorofila e sua maior disponibilidade favorece a produção de fotoassimilados (Fageria \& Stone 2003). Isto, provavelmente, favoreceu o maior crescimento das plantas, em altura. Resultado semelhante foi observado por Fidelis et al. (2012), com arroz de terras altas cultivado em condições de baixa e alta disponibilidade de N, em Gurupi (TO). Porém, na segunda safra, quando se empregou a cultivar IAC 202, não foram observadas diferenças, tanto para os modos de preparo do solo quanto para as doses de $\mathrm{N}$.

$\mathrm{O}$ plantio direto propiciou maior concentração de $\mathrm{N}$ nas folhas bandeira coletadas por ocasião do florescimento, na safra 2003/2004 (Tabela 1). Isto pode ter ocorrido devido ao fato de as plantas apresentarem menor crescimento neste sistema de cultivo, ocorrendo maior concentração do nutriente nas folhas. Para as doses de N, os dados se ajustaram à equação quadrática e as plantas apresentaram maior

Tabela 1. Altura de plantas, concentração de $\mathrm{N}$ na folha bandeira e número de panículas $\mathrm{m}^{-2}$ em arroz de terras altas irrigado por aspersão, em função do preparo do solo e doses de nitrogênio em cobertura (Selvíria, MS, safras 2003/2004 e 2004/2005).

\begin{tabular}{|c|c|c|c|c|c|c|}
\hline \multirow{2}{*}{ Causas da variação } & \multicolumn{2}{|c|}{ Altura de plantas $(\mathrm{cm})$} & \multicolumn{2}{|c|}{$\mathrm{N}$ na folha bandeira $\left(\mathrm{g} \mathrm{kg}^{-1}\right)$} & \multicolumn{2}{|c|}{ Panículas $\mathrm{m}^{-2}$} \\
\hline & $2003 / 2004$ & $2004 / 2005$ & $2003 / 2004$ & $2004 / 2005$ & $2003 / 2004$ & $2004 / 2005$ \\
\hline \multicolumn{7}{|c|}{ Preparo do solo } \\
\hline Escarificador & $90,10 \mathrm{a}$ & 94,40 & $34,50 \mathrm{~b}$ & 27,20 & $241,00 \mathrm{a}$ & $262,00 \mathrm{a}$ \\
\hline Grade aradora & $85,80 \mathrm{~b}$ & 90,80 & $34,60 \mathrm{~b}$ & 26,10 & $224,00 \mathrm{ab}$ & $250,00 \mathrm{ab}$ \\
\hline Plantio direto & $82,20 \mathrm{c}$ & 91,80 & $36,30 \mathrm{a}$ & 26,70 & $210,00 \mathrm{~b}$ & $233,00 \mathrm{~b}$ \\
\hline \multicolumn{7}{|c|}{ Dose de $N$ em cobertura $\left(\mathrm{kg} \mathrm{ha}^{-1}\right)$} \\
\hline 0 & $85,00^{(a)}$ & 94,80 & $33,11^{(b)}$ & $28,96^{(\mathrm{c})}$ & $199,00^{(\mathrm{d})}$ & 238,00 \\
\hline 25 & 85,20 & 93,20 & 34,23 & 26,14 & 215,00 & 248,00 \\
\hline 50 & 86,10 & 92,40 & 35,56 & 25,64 & 210,00 & 245,00 \\
\hline 75 & 85,60 & 89,90 & 35,81 & 25,99 & 227,00 & 244,00 \\
\hline 100 & 86,70 & 93,00 & 36,70 & 26,51 & 248,00 & 254,00 \\
\hline 125 & 88,30 & 90,60 & 35,66 & 27,21 & 250,00 & 258,00 \\
\hline \multicolumn{7}{|c|}{ Teste F - Valores de F } \\
\hline Preparo & $33,10 * *$ & $2,04^{\mathrm{ns}}$ & $10,98 * *$ & $1,85^{\mathrm{ns}}$ & $3,49 *$ & $6,42 * *$ \\
\hline Nitrogênio (N) & $2,98^{*}$ & $0,97^{\mathrm{ns}}$ & $8,60 * *$ & $4,84 * *$ & $3,04 *$ & $0,85^{\text {ns }}$ \\
\hline Preparo x N & $1,31^{\mathrm{ns}}$ & $0,65^{\text {ns }}$ & $1,60^{\mathrm{ns}}$ & $1,14^{\mathrm{ns}}$ & $1,25^{\mathrm{ns}}$ & $0,89^{\text {ns }}$ \\
\hline RL & $4,52 *$ & $2,42^{\text {ns }}$ & $30,99 * *$ & $3,57^{\mathrm{ns}}$ & $13,87^{* *}$ & $3,24^{\mathrm{ns}}$ \\
\hline RQ & $1,56^{\mathrm{ns}}$ & $0,49^{\text {ns }}$ & $9,76^{* *}$ & $12,04 * *$ & $0,11^{\mathrm{ns}}$ & $0,13^{\mathrm{ns}}$ \\
\hline DMS & 2,96 & 4,43 & 1,34 & 1,40 & 28,98 & 24,49 \\
\hline CV (\%) & 3,90 & 6,90 & 4,30 & 6,20 & 18,40 & 11,20 \\
\hline
\end{tabular}


teor de $\mathrm{N}$ nas folhas na dose de $94 \mathrm{~kg} \mathrm{ha}^{-1}$. Entretanto, é interessante mencionar que todos os valores obtidos estão dentro da faixa adequada para a cultura, que, de acordo com Cantarella \& Furlani (1996), é de 27-35 $\mathrm{g} \mathrm{kg}^{-1}$. Para a safra 2004/2005, houve efeito significativo apenas para doses de $\mathrm{N}$, e os dados se ajustaram, também, à equação quadrática.

Tanto na safra 2003/2004 como na 2004/2005, o preparo do solo com escarificador proporcionou maior número de panículas por área, em relação ao plantio direto, porém, ambos não diferiram do preparo com grade aradora. Na safra 2003/2004, para as doses de $\mathrm{N}$, os dados de panículas $\mathrm{m}^{-2} \mathrm{se}$ ajustaram à equação linear crescente (Tabela 1). Neste caso, o $\mathrm{N}$ aplicado deve ter propiciado melhor desenvolvimento de perfilhos e, consequentemente, contribuído para aumentar o número de panículas por área. $\mathrm{O}$ número de espiguetas panícula ${ }^{-1}$ não foi influenciado pelos tipos de preparo do solo e pelas doses de $\mathrm{N}$, independentemente da safra agrícola (Tabela 2), sendo o mesmo observado quanto aos efeitos da adubação nitrogenada (Tabela 2). Arf et al. (2005) também verificaram, na cultura do arroz de terras altas, que a adição de $\mathrm{N}$ não influenciou no número de espiguetas panícula-1 ${ }^{-1}$.
$\mathrm{O}$ número de espiguetas cheias panícula ${ }^{-1}$ também foi dependente do preparo do solo, na safra 2003/2004, onde o preparo com escarificador propiciou maior número de espiguetas cheias, em relação ao plantio direto (Tabela 2). $\mathrm{O}$ fornecimento de $\mathrm{N}$ não alterou o percentual de espiguetas cheias. $\mathrm{O}$ mesmo foi observado por Arf et al. (2003) e Neves et al. (2004), cultivando o arroz nas mesmas condições edafoclimáticas do presente estudo, e por Farinelli et al. (2004), em estudo no município de Jaboticabal (SP). Apesar de pouco expressivo, pôde-se verificar que, na safra 2004/2005, à medida em que foram aumentadas as doses de $\mathrm{N}$, houve aumento no número de espiguetas chochas panícula ${ }^{-1}$ até a dose estimada de $63 \mathrm{~kg} \mathrm{ha}^{-1}$ de N (Tabela 2), assim como observado por Bordin et al. (2003), que avaliaram esta variável em função da aplicação de quatro doses de $\mathrm{N}\left(0 \mathrm{~kg} \mathrm{ha}^{-1}, 25 \mathrm{~kg} \mathrm{ha}^{-1}, 50 \mathrm{~kg} \mathrm{ha}^{-1}\right.$ e $\left.75 \mathrm{~kg} \mathrm{ha}^{-1}\right)$, em arroz cultivado em sucessão ao feijoeiro, no município de Jaboticabal (SP).

Verificou-se, também, que o preparo do solo influenciou na massa de 100 grãos apenas na safra 2003/2004 (Tabela 3). O preparo com grade aradora e o plantio direto propiciaram maior massa de 100 grãos, em relação ao preparo realizado com

Tabela 2. Número de espiguetas totais, cheias e chochas por panícula em arroz de terras altas irrigado por aspersão, em função do preparo do solo e adubação nitrogenada em cobertura (Selvíria, MS, safras 2003/2004 e 2004/2005).

\begin{tabular}{|c|c|c|c|c|c|c|}
\hline \multirow{2}{*}{ Causas da variação } & \multicolumn{2}{|c|}{ Espiguetas totais } & \multicolumn{2}{|c|}{ Espiguetas cheias } & \multicolumn{2}{|c|}{ Espiguetas chochas } \\
\hline & $2003 / 2004$ & $2004 / 2005$ & $2003 / 2004$ & $2004 / 2005$ & $2003 / 2004$ & $2004 / 2005$ \\
\hline \multicolumn{7}{|c|}{ Preparo do solo } \\
\hline Escarificador & $115,30 \mathrm{a}$ & $156,20 \mathrm{a}$ & $89,60 \mathrm{a}$ & $136,60 \mathrm{a}$ & $25,70 \mathrm{a}$ & $19,70 \mathrm{a}$ \\
\hline Grade aradora & $110,20 \mathrm{a}$ & $151,60 \mathrm{a}$ & $82,80 \mathrm{ab}$ & $132,30 \mathrm{a}$ & $27,50 \mathrm{a}$ & $19,30 \mathrm{a}$ \\
\hline Plantio direto & $108,70 \mathrm{a}$ & $145,00 \mathrm{a}$ & $79,30 \mathrm{~b}$ & $124,90 \mathrm{a}$ & $29,40 \mathrm{a}$ & $20,00 \mathrm{a}$ \\
\hline \multicolumn{7}{|c|}{ Dose de $N$ em cobertura $\left(\mathrm{kg} \mathrm{ha}^{-1}\right)$} \\
\hline 0 & 113,00 & 142,00 & 85,80 & 126,30 & 27,10 & $15,60^{(a)}$ \\
\hline 25 & 112,50 & 149,60 & 83,70 & 127,60 & 28,80 & 22,00 \\
\hline 50 & 109,70 & 150,20 & 80,70 & 129,90 & 29,00 & 23,20 \\
\hline 75 & 110,10 & 165,80 & 82,60 & 139,30 & 27,40 & 24,50 \\
\hline 100 & 110,30 & 151,10 & 84,60 & 133,70 & 25,60 & 17,40 \\
\hline 125 & 112,60 & 146,80 & 85,50 & 130,80 & 27,00 & 16,00 \\
\hline \multicolumn{7}{|c|}{ Teste F - Valores de F } \\
\hline Preparo & $1,89^{\mathrm{ns}}$ & $0,8909^{\mathrm{ns}}$ & $5,49 * *$ & $1,2068^{\mathrm{ns}}$ & $1,70^{\mathrm{ns}}$ & $0,11^{\mathrm{ns}}$ \\
\hline Nitrogênio (N) & $0,17^{\mathrm{ns}}$ & $0,8995^{\mathrm{ns}}$ & $0,37^{\mathrm{ns}}$ & $0,3861^{\mathrm{ns}}$ & $0,37^{\mathrm{ns}}$ & $6,91 * *$ \\
\hline Preparo x N & $1,89^{\mathrm{ns}}$ & $1,1019^{\mathrm{ns}}$ & $1,92^{\text {ns }}$ & $1,0594^{\mathrm{ns}}$ & $0,40^{\mathrm{ns}}$ & $1,71^{\mathrm{ns}}$ \\
\hline $\mathrm{RL}$ & $0,079^{\text {ns }}$ & $0,39^{\text {ns }}$ & $0,01^{\mathrm{ns}}$ & $0,62^{\text {ns }}$ & $0,44^{\mathrm{ns}}$ & $0,17^{\mathrm{ns}}$ \\
\hline RQ & $0,63^{\mathrm{ns}}$ & $2,42^{\mathrm{ns}}$ & $1,47^{\mathrm{ns}}$ & $0,57^{\mathrm{ns}}$ & $0,25^{\mathrm{ns}}$ & $21,85^{* *}$ \\
\hline DMS & 10,33 & 20,45 & 9,67 & 18,28 & 3,78 & 3,85 \\
\hline CV (\%) & 11,00 & 19,40 & 13,10 & 19,90 & 25,40 & 28,10 \\
\hline
\end{tabular}


escarificador. Quanto às doses de $\mathrm{N}$, não houve efeito significativo na massa de 100 grãos, em ambas as safras (Tabela 3). Diversos autores têm constatado que a massa de 100 grãos é pouco influenciada pelo fornecimento de N (Arf et al. 2003, Farinelli et al. 2004, Cazetta et al. 2008, Hernandes et al. 2010, Fidelis et al. 2012). De fato, a massa de 100 grãos parece ser um caráter varietal bastante estável (Yoshida 1981).

Observou-se, ainda, que, na safra 2003/2004, o preparo do solo influenciou na massa hectolítrica, onde o plantio direto apresentou valor superior ao obtido no preparo com escarificador e grade aradora (Tabela 3). O mesmo foi observado por Arf et al. (2005). Em relação às doses de $N$, na safra 2004/2005, houve efeito significativo, sendo que os dados se ajustaram à equação quadrática.

Verificou-se que, nas duas safras, o preparo do solo interferiu na produtividade da cultura (Tabela 3 ). $\mathrm{O}$ uso de escarificador propiciou a obtenção de maior produtividade, em relação ao preparo realizado com grade aradora e plantio direto. Arf et al. (2001) também observaram que o preparo do solo com escarificador, em safra com presença de veranico, apresentou resultados superiores ao preparo com grade aradora, para a produção de grãos de arroz. Este resultado deve estar relacionado a um possível aprofundamento do sistema radicular, em função da criação de um ambiente mais propício ao desenvolvimento radicular em profundidade, aproveitando água e nutrientes em um maior volume de solo, em relação aos outros sistemas. Kamimura et al. (2009) também verificaram que o sistema de preparo do solo com escarificador + grade niveladora foi o que resultou em melhores condições físicas para o desenvolvimento da cultura do arroz, quando comparado com o plantio direto e o preparo com grade aradora + grade niveladora.

Quanto aos efeitos da dose de $\mathrm{N}$ na produtividade, não houve diferenças na safra 2003/2004. Já na safra 2004/2005, houve efeito significativo e os dados se ajustaram à equação quadrática, sendo que a aplicação de $62 \mathrm{~kg} \mathrm{ha}^{-1}$ de N, em cobertura, propiciou a maior produtividade $\left(2.755 \mathrm{~kg} \mathrm{ha}^{-1}\right)$ (Tabela 3$)$. Em diversos trabalhos, como os de Bordin et al. (2003), Arf et al. (2005), Buzetti et al. (2006), Cazetta et al. (2008), Hernandes et al. (2010) e Fidelis et al. (2012), são citadas respostas significativas, com incrementos na produtividade, em função da aplicação de N.

Para o rendimento de benefício, não houve diferença em função do preparo do solo e da adubação nitrogenada em cobertura, nas duas safras (Tabela 4).

Tabela 3. Massa de 100 grãos, massa hectolítrica e produtividade de grãos de arroz de terras altas irrigado por aspersão, em função do preparo do solo e adubação nitrogenada em cobertura (Selvíria, MS, safras 2003/2004 e 2004/2005).

\begin{tabular}{|c|c|c|c|c|c|c|}
\hline \multirow{2}{*}{ Causas da variação } & \multicolumn{2}{|c|}{ Massa de 100 grãos (g) } & \multicolumn{2}{|c|}{ Massa hectolítrica $\left(\mathrm{kg} \mathrm{hL}^{-1}\right)$} & \multicolumn{2}{|c|}{ Produtividade $\left(\mathrm{kg} \mathrm{ha}^{-1}\right)$} \\
\hline & $2003 / 2004$ & $2004 / 2005$ & $2003 / 2004$ & $2004 / 2005$ & $2003 / 2004$ & $2004 / 2005$ \\
\hline \multicolumn{7}{|c|}{ Preparo do solo } \\
\hline Escarificador & $2,32 \mathrm{~b}$ & $2,24 \mathrm{a}$ & $47,52 \mathrm{~b}$ & 48,24 & $2.224,00 \mathrm{a}$ & $3.120,00 \mathrm{a}$ \\
\hline Grade aradora & $2,62 \mathrm{a}$ & $2,20 \mathrm{a}$ & $46,63 \mathrm{~b}$ & 47,14 & $1.936,00 \mathrm{~b}$ & $2.552,00 \mathrm{~b}$ \\
\hline Plantio direto & $2,46 \mathrm{ab}$ & $2,14 \mathrm{a}$ & $50,49 \mathrm{a}$ & 46,07 & $1.750,00 \mathrm{~b}$ & $1.948,00 \mathrm{c}$ \\
\hline \multicolumn{7}{|c|}{ Dose de $N$ em cobertura $\left(\mathrm{kg} \mathrm{ha}^{-1}\right)$} \\
\hline 0 & 2,36 & 2,22 & 49,24 & $46,40^{(a)}$ & $1.899,00$ & $2.383,00^{(\mathrm{b})}$ \\
\hline 25 & 2,53 & 2,16 & 47,34 & 46,67 & $1.901,00$ & $2.553,00$ \\
\hline 50 & 2,50 & 2,26 & 48,56 & 47,02 & $2.014,00$ & $2.757,00$ \\
\hline 75 & 2,59 & 2,16 & 49,17 & 47,00 & $1.964,00$ & $2.897,00$ \\
\hline 100 & 2,37 & 2,20 & 46,22 & 46,04 & $2.014,00$ & $2.456,00$ \\
\hline 125 & 2,44 & 2,17 & 48,73 & 45,86 & $2.025,00$ & $2.296,00$ \\
\hline \multicolumn{7}{|c|}{ Teste F - Valores de F } \\
\hline Preparo & $7,24 * *$ & $2,81^{\mathrm{ns}}$ & $10,09 * *$ & $1,11^{\mathrm{ns}}$ & $11,13^{* *}$ & $50,65 * *$ \\
\hline Nitrogênio (N) & $1,46^{\mathrm{ns}}$ & $1,02^{\mathrm{ns}}$ & $1,75^{\text {ns }}$ & $2,71^{*}$ & $0,32^{\mathrm{ns}}$ & $4,03 * *$ \\
\hline Preparo x N & $0,19^{\text {ns }}$ & $0,62^{\mathrm{ns}}$ & $1,24^{\mathrm{ns}}$ & $0,62^{\mathrm{ns}}$ & $0,76^{\mathrm{ns}}$ & $0,93^{\mathrm{ns}}$ \\
\hline RL & $0,00074^{\mathrm{ns}}$ & $0,078^{\text {ns }}$ & $0,49^{\text {ns }}$ & $0,07^{\mathrm{ns}}$ & $1,17^{\mathrm{ns}}$ & $0,07^{\mathrm{ns}}$ \\
\hline RQ & $3,35^{\mathrm{ns}}$ & $14,91^{\mathrm{ns}}$ & $0,42^{\mathrm{ns}}$ & $3,89 *$ & $0,05^{\mathrm{ns}}$ & $14,91 * *$ \\
\hline DMS & 0,23 & 0,12 & 2,75 & 3,50 & 309,29 & 356,02 \\
\hline $\mathrm{CV}(\%)$ & 10,80 & 6,20 & 6,50 & 10,60 & 17,80 & 15,90 \\
\hline
\end{tabular}


Tabela 4. Rendimento de benefício, rendimento de grãos inteiros e grãos quebrados em arroz de terras altas irrigado por aspersão, em função do preparo do solo e adubação nitrogenada em cobertura (Selvíria, MS, safras 2003/2004 e 2004/2005).

\begin{tabular}{|c|c|c|c|c|c|c|}
\hline \multirow{2}{*}{ Causas da variação } & \multicolumn{2}{|c|}{ Rendimento de benefício (\%) } & \multicolumn{2}{|c|}{ Rendimento de inteiros (\%) } & \multicolumn{2}{|c|}{ Grãos quebrados (\%) } \\
\hline & $2003 / 2004$ & $2004 / 2005$ & $2003 / 2004$ & $2004 / 2005$ & $2003 / 2004$ & $2004 / 2005$ \\
\hline \multicolumn{7}{|c|}{ Preparo do solo } \\
\hline Escarificador & $68,90 \mathrm{a}$ & $67,10 \mathrm{a}$ & $48,40 \mathrm{a}$ & $51,60 \mathrm{a}$ & $19,20 \mathrm{~b}$ & $15,50 \mathrm{ab}$ \\
\hline Grade & $70,20 \mathrm{a}$ & $67,80 \mathrm{a}$ & $49,30 \mathrm{a}$ & $52,70 \mathrm{a}$ & $20,10 \mathrm{ab}$ & $14,90 \mathrm{~b}$ \\
\hline Plantio direto & $69,70 \mathrm{a}$ & $66,20 \mathrm{a}$ & $47,60 \mathrm{a}$ & $48,70 \mathrm{a}$ & $21,90 \mathrm{a}$ & $17,50 \mathrm{a}$ \\
\hline \multicolumn{7}{|c|}{ Dose de $\mathrm{N}$ em cobertura $\left(\mathrm{kg} \mathrm{ha}^{-1}\right)$} \\
\hline 0 & 69,20 & 66,30 & 48,10 & 50,90 & 19,90 & 15,20 \\
\hline 25 & 69,30 & 65,70 & 47,10 & 50,00 & 21,50 & 15,80 \\
\hline 50 & 70,80 & 69,80 & 48,50 & 55,70 & 20,80 & 14,20 \\
\hline 75 & 69,80 & 65,70 & 49,00 & 47,00 & 20,50 & 18,50 \\
\hline 100 & 69,80 & 68,60 & 49,60 & 52,00 & 20,10 & 16,60 \\
\hline 125 & 68,80 & 66,00 & 47,90 & 50,40 & 19,10 & 15,10 \\
\hline \multicolumn{7}{|c|}{ Teste F - Valores de F } \\
\hline Preparo & $1,05^{\mathrm{ns}}$ & $0,58^{\mathrm{ns}}$ & $0,84^{\mathrm{ns}}$ & $2,98^{\mathrm{ns}}$ & $4,27 *$ & $3,59 *$ \\
\hline Nitrogênio (N) & $0,67^{\mathrm{ns}}$ & $1,31^{\mathrm{ns}}$ & $0,44^{\mathrm{ns}}$ & $2,80^{*}$ & $0,73^{\mathrm{ns}}$ & $2,26^{\mathrm{ns}}$ \\
\hline Preparo x N & $1,23^{\text {ns }}$ & $0,64^{\mathrm{ns}}$ & $2,22^{\mathrm{ns}}$ & $0,58^{\text {ns }}$ & $1,44^{\mathrm{ns}}$ & $0,61^{\mathrm{ns}}$ \\
\hline RL & $0,14^{\mathrm{ns}}$ & $0,04^{\mathrm{ns}}$ & $0,37^{\mathrm{ns}}$ & $0,12^{\mathrm{ns}}$ & $1,15^{\mathrm{ns}}$ & $0,57^{\mathrm{ns}}$ \\
\hline RQ & $2,33^{\mathrm{ns}}$ & $1,12^{\mathrm{ns}}$ & $0,34^{\mathrm{ns}}$ & $0,13^{\mathrm{ns}}$ & $1,86^{\mathrm{ns}}$ & $1,59^{\mathrm{ns}}$ \\
\hline DMS & 2,10 & 3,71 & 3,24 & 4,10 & 2,33 & 2,46 \\
\hline CV $(\%)$ & 4,30 & 7,90 & 9,60 & 11,50 & 16,40 & 22,10 \\
\hline
\end{tabular}

Médias seguidas de letras iguais, nas colunas, não diferem estatisticamente entre si, pelo teste Tukey, a $5 \%(*)$ e $1 \%(* *)$. ns Não significativo. RL: regressão linear; RQ: regressão quadrática.

Os valores foram de, arpoximadamente, $68 \%$, índice considerado adequado para a cultura. Também na Tabela 4, verifica-se que, para o rendimento industrial, não houve diferenças entre os tratamentos utilizados nas duas safras. Já Bordin et al. (2003), trabalhando com doses de $\mathrm{N}\left(0 \mathrm{~kg} \mathrm{ha} \mathrm{k}^{-1}, 25 \mathrm{~kg} \mathrm{ha}^{-1}\right.$, $\left.50 \mathrm{~kg} \mathrm{ha}^{-1} \mathrm{e} 75 \mathrm{~kg} \mathrm{ha}^{-1}\right)$, observaram maior rendimento com a dose de $75 \mathrm{~kg} \mathrm{ha}^{-1}$. Para grãos quebrados, houve diferença significativa apenas para preparo do solo, nas duas safras (Tabela 4). O tratamento com plantio direto foi o que apresentou a maior quantidade de grãos quebrados, nas duas safras.

\section{CONCLUSÕES}

1. O preparo do solo com escarificador propiciou maior produtividade de arroz, em relação ao preparo realizado com grade aradora e plantio direto.

2. A cultivar IAC 202 respondeu à adubação nitrogenada em cobertura, atingindo produtividade máxima na dose de $62 \mathrm{~kg} \mathrm{ha}^{-1}$ de nitrogênio.

3. Os rendimentos de benefício e de grãos inteiros do arroz de terras altas não foram influenciados pelo preparo do solo.
4. A adubação nitrogenada em cobertura não afetou o rendimento industrial do arroz de terras altas irrigado por aspersão, independentemente do tipo de preparo do solo.

\section{REFERÊNCIAS}

ARF, O. et al. Manejo do solo e época de aplicação de nitrogênio na produção de arroz de terras altas. Acta Scientiarum Agronomy, Maringá, v. 27, n. 2, p. 215-223, 2005.

ARF, O. et al. Preparo do solo, irrigação por aspersão e rendimento de engenho do arroz de terras altas. Scientia Agricola, Piracicaba, v. 59, n. 2, p. 321-326, 2002.

ARF, O. et al. Resposta de cultivares de arroz de sequeiro ao preparo do solo e à irrigação por aspersão. Pesquisa Agropecuária Brasileira, Brasília, DF, v. 36, n. 6, p. 871879, 2001.

ARF, O. et al. Soil management and nitrogen fertilization for sprinkler-irrigated upland rice cultivars. Scientia Agricola, Piracicaba, v. 60, n. 2, p. 345-352, 2003.

BORDIN, L. et al. Sucessão de cultivo de feijão-arroz com doses de adubação nitrogenada após adubação verde, em plantio direto. Bragantia, Campinas, v. 62 , n. 3, p. 235 241, 2003. 
BUZETTI, S. et al. Resposta de cultivares de arroz a doses de nitrogênio e do regulador de crescimento cloreto de clormequat. Pesquisa Agropecuária Brasileira, Brasília, DF, v. 41, n. 12, p. 1731-1737, 2006.

CANTARELLA, H.; FURLANI, P. R. Arroz de sequeiro. In: RAIJ, B. V. et al. (Eds.). Recomendações de adubação e calagem para o Estado de São Paulo. 2. ed. Campinas: IAC, 1996. p. 48-49 (Boletim técnico, 100).

CAZETTA, D. A. et al. Desempenho do arroz de terras altas com a aplicação de doses de nitrogênio e em sucessão às culturas de cobertura do solo em sistema de plantio direto. Bragantia, Campinas, v. 67, n. 2, p. 471-479, 2008.

EMPRESA BRASILEIRA DE PESQUISA AGROPECUÁRIA (Embrapa). Centro Nacional de Pesquisa de Solos. Sistema brasileiro de classificação de solos. 2. ed. Rio de Janeiro: Embrapa, 2006.

FAGERIA, N. K. Adubação e nutrição mineral da cultura de arroz. Rio de Janeiro: Embrapa, 1984.

FAGERIA, N. K.; STONE, L. F. Manejo do nitrogênio. In: FAGERIA, N. K.; STONE, L. F.; SANTOS, A. B. dos. Manejo da fertilidade do solo para o arroz irrigado. Santo Antônio de Goiás: Embrapa Arroz e Feijão, 2003. p. 51-94.

FARINELLI, R. et al. Características agronômicas de arroz de terras altas sob plantio direto e adubação nitrogenada e potássica. Revista Brasileira de Ciência do Solo, Viçosa, v. 28, n. 3, p. 447-454, 2004.

FIDELIS, R. R. et al. Eficiência do uso de nitrogênio em genótipos de arroz de terras altas. Pesquisa Agropecuária Tropical, Goiânia, v. 42, n. 1, p. 124-128, 2012.

HERNANDES, A. et al. Doses, fontes e épocas de aplicação de nitrogênio em cultivares de arroz. Ciência e Agrotecnologia, Lavras, v. 34, n. 2, p. 307-312, 2010.

KAMIMURA, K. M. et al. Propriedades físicas de um Latossolo Vermelho sob cultivo do arroz de terras altas em diferentes manejos do solo e água. Bragantia, Campinas, v. 68, n. 3, p. 723-731, 2009.
MALAVOlTA, E.; VITTI, G. C.; OLIVEIRA, S. A. Avaliação do estado nutricional das plantas: princípios e aplicações. 2. ed. Piracicaba: Potafos, 1997.

NEVES, M. B. et al. Doses e épocas de aplicação de nitrogênio em cobertura em dois cultivares de arroz com irrigação complementar. Acta Scientiarum Agronomy, Maringá, v. 26, n. 4, p. 429-435, 2004.

REIS, M. de S. et al. Comportamento de genótipos de arroz de terras altas sob sistemas de plantio direto e convencional. Pesquisa Agropecuária Tropical, Goiânia, v. 37, n. 4, p. 227-232, 2007.

ROJAS, C. A. L. et al. Volatilização de amônia da ureia alterada por sistemas de preparo do solo e plantas de cobertura invernais no centro-sul do Paraná. Revista Brasileira de Ciência do Solo, Viçosa, v. 36, n. 1, p. 261270, 2012.

SEGUY, L.; BOUZINAC, S. Arroz de sequeiro na Fazenda Progresso: $4550 \mathrm{~kg} / \mathrm{ha}$. Informações Agronômicas, Piracicaba, n. 58, p. 1-3, 1992.

SEGUY, L.; BOUZINAC, S. R. P.; PACHECO, A. Perspectiva de fixação da agricultura na região centronorte do Mato Grosso. Goiânia: Embrapa-CNPAF, 1989.

SEGUY, L. et al. O plantio direto do arroz de sequeiro de alta tecnologia na Zona Tropical Úmida do centro-norte do Mato Grosso - Brasil. Sorriso: Agronorte, 1998.

SOARES, A. A. Desvendando o segredo do insucesso do plantio direto do arroz de terras altas. Informações Agropecuárias, Belo Horizonte, v. 25, n. 222, p. 61-69, 2004.

YOSHIDA, S. Growth and development of the rice plant. In: YOSHIDA, S. Fundamentals of rice crop science. Los Baños: International Rice Research Institute, 1981. p. 1-63. 